\title{
Synthesis and Characterisation of Piperine-loaded Starch Nanoparticles
}

\author{
Wan-Hong Chong, ${ }^{1}$ Suk-Fun Chin, ${ }^{1 *}$ Suh-Cem Pang ${ }^{1}$ and Kuan-Ying Kok ${ }^{2}$ \\ ${ }^{1}$ Faculty of Resource Science and Technology, Universiti Malaysia Sarawak, \\ 94300 Kota Samarahan, Sarawak, Malaysia \\ ${ }^{2}$ Malaysian Nuclear Agency, Bangi, 43000 Kajang, Selangor, Malaysia \\ "Corresponding author: sfchin@unimas.my
}

Published online: 25 April 2020

To cite this article: Chong, W-H. et al. (2020). Synthesis and characterisation of piperineloaded starch nanoparticles. J. Phys. Sci., 31(1), 57-68. https://doi.org/10.21315/ jps2020.31.1.4

To link to this article: https://doi.org/10.21315/jps2020.31.1.4

\begin{abstract}
This study aimed to explore the potential application of starch nanoparticles as the nanocarriers for the controlled release of piperine. Starch nanoparticles with mean particle sizes ranging from $50 \mathrm{~nm}$ to $200 \mathrm{~nm}$ have been synthesised as nanocarriers for encapsulation of piperine. Piperine has been successfully loaded onto starch nanoparticles via the in-situ nanoprecipitation method. The loading capacity of piperine was affected by the synthesis conditions such as types and concentrations of surfactants as well as initial piperine concentrations. Under optimum conditions, starch nanoparticles exhibited a maximum piperine loading capacity of $4.74 \mathrm{mg} \mathrm{mg}^{-1}$. Piperine was observed to release out from starch nanoparticles in a slow and steady manner over a period of $168 \mathrm{~h}$ under physiological $\mathrm{pH}$.
\end{abstract}

Keywords: Piperine, starch nanoparticles, nanocarriers, release studies, syhthesis and characterisation

\section{INTRODUCTION}

Piperine is the major alkaloid of the black pepper, and it is responsible for the spicy flavour of the black pepper. Piperine is a yellow crystalline compound and it is a weak base compound particle with low water solubility $\left(40 \mathrm{mg} \mathrm{l}^{-1}\right.$ at $18^{\circ} \mathrm{C}$ ). It is not reactive in solid form but becomes reactive after dissolved in solution. ${ }^{1}$ Traditionally, piperine had been used mainly for culinary purposes but it has been proven to have excellent pharmacological properties. In addition, piperine has demonstrated to have biotransformative effects and could enhance the bioavailability of therapeutic drugs. ${ }^{2}$ 
However, the therapeutic properties of piperine are yet to be fully realised due to its low water solubility $\left(40 \mathrm{mg}^{-1}\right.$ at $\left.18^{\circ} \mathrm{C}\right)$, poor bioavailability and cytotoxicity at high concentrations. These shortcomings have prompted research efforts to encapsulate piperine onto various nano-carriers in order to improve its water solubility and bioavailability. Piperine encapsulated polyethylene glycolpolylactide-co-glycolide nanoparticles (PEG-PLGA) have been formulated for adjuvant cancer chemotherapy against drug-resistant breast cancers. ${ }^{3}$ Piperineloaded chitosan nanoparticles were shown to effectively inhibit apoptotic and inflammatory factors expressions in Alzheimer's disease model. ${ }^{4}$ This study has proven that piperine-loaded chitosan nanoparticles could lower the dosages and at the same time enhance the efficacy as compared to the corresponding suspension form. Bhalekar et al., on the other hand, formulated piperine solid lipid nanoparticle (SLN) using the melt emulsification method for the treatment of rheumatoid arthritis. ${ }^{5}$ More recently, piperine was loaded onto chitosan nanoparticles for the treatment of epilepsy disorder. This study has demonstrated that piperine-loaded chitosan nanoparticles have a more significant inhibitory effect on the seizures' behavioural signs as compared to the free piperine. ${ }^{6}$

Starch is a natural biopolymer that can be found abundantly from many green plants. Different starch sources will represent a variety of amylose and amylopectin contents which affect the thermal properties. ${ }^{7}$ Starch nanoparticles are highly hydrophilic with plenty of hydroxyl groups on their surface and easily swell while immersed in aqueous media. ${ }^{8}$ Starch nanoparticles have been reported studied as fat replacers, drug carriers, packaging materials in foods, cosmetics and pharmaceuticals industry. ${ }^{9}$

In this study, we report the use of a simple in-situ nano-precipitation method to synthesise piperine-loaded starch nanoparticles. Starch nanoparticles are promising polysaccharide-based nanocarriers for piperine as they are renewable, abundantly available, low-cost and biodegradable. ${ }^{10,11}$ The same procedure was repeated by adding various types of surfactants such as Polysorbate 80 (Tween 80 ), sorbitan monostearate (Span 60) and cetrimonium bromide (CTAB) as surfactants in order to study the effects of surfactant on the loading capacity of piperine. The hydrophobic nature of the surfactants was exploited to assist in enhancing the loading capacity of the piperine in the starch nanoparticles. Various formulation parameters such as piperine concentrations, the use of surfactant that affected the loading capacity and the release kinetics profiles of piperine were evaluated under the physiological conditions. 


\section{EXPERIMENTAL}

\subsection{Materials and Reagents}

Native sago starch powder was obtained from a local grocery shop in Kuching (Sarawak, Malaysia). Tween 80, Span 60 and CTAB were obtained from R \& $\mathrm{M}$, Merck and JT Baker, respectively. Commercial piperine was purchased from Aldrich. Sodium hydroxide was purchased from Mallinckrodt. Absolute ethanol was obtained from Hamburg. Ultrapure water $(18.2 \mathrm{M} \Omega \mathrm{cm})$ was used in all syntheses.

\subsection{Synthesis of Piperine-loaded Starch Nanoparticles}

Starch solution $(1 \% \mathrm{w} / \mathrm{v})$ was prepared by dissolving $1.0 \mathrm{~g}$ of native sago starch in $100 \mathrm{ml} \mathrm{NaOH}$ :urea (NU) (0.8:1 wt\%) aqueous solvent. ${ }^{12}$ About $3.0 \mathrm{mg} \mathrm{ml}^{-1}$ of piperine was dissolved in $30 \mathrm{ml}$ of absolute ethanol containing $0.3 \mathrm{mg} \mathrm{m}^{-1}$ surfactant and the mixture was stirred continuously until it is homogeneous. A total of $1 \mathrm{ml}$ starch solution was added dropwise to the mixture and continued to stir in order to obtain a homogeneous mixture. Piperine was loaded in-situ onto starch nanoparticles as the starch nanoparticles formed during the nano-precipitation process. The piperine loaded starch nanoparticles obtained were centrifuged and washed several times with ethanol solution to remove free piperine that was adhered to the surface of starch nanoparticles.

\subsection{Characterisation of Piperine-loaded Starch Nanoparticles}

The morphology of piperine-loaded starch nanoparticles was characterised using scanning electron microscope (SEM, model JEOL-SM 6390 LA) and field emission scanning electron microscopy (FESEM, Carl Zeiss Gemini SEM 500). SEM was operated at $10 \mathrm{kV}$ and current $60-70 \mu \mathrm{A}$. Samples were dropped coated on stainless steel plates. It was then dried inside an oven (model Memmert UNB 300) at $50^{\circ} \mathrm{C}$ and coated with gold $(\mathrm{Au})$ for $2 \mathrm{~min}$. In contrast, FESEM was operated with an accelerating voltage of $20 \mathrm{kV}$ under high vacuum mode and the sample preparation was done by coated with a layer of platinum using Auto Fine Coater (model JEOL JFC-1600). The mean particle size of samples was calculated based on average particle sizes of 100 particles. SmileView software was used to measure particle diameters of randomly selected 100 nanoparticles. 


\subsection{Loading Capacity of Piperine}

The piperine-loaded starch nanoparticles were isolated from solution by centrifugation and the UV absorbance of free piperine was measured at a wavelength of $343 \mathrm{~nm}$ using a UV-Vis spectrophotometer (Lambda 650, Perkin Elmer). The concentration of piperine was quantified with reference to a regression equation (liner plot with a slope of 0.9794 ) obtained from the constructed calibration curve of piperine in absolute ethanol solution. The loading capacity of piperine onto starch nanoparticles was calculated using Equation 1:

$$
\text { Loading capacity }\left(\frac{\mathrm{mg}}{\mathrm{mg}}\right)=\frac{[\text { piperine }]_{\text {tot }}-[\text { piperine }]_{\text {free }}}{\text { Total weight of nanoparticles }}
$$

where [piperine $]_{\text {tot }}$ is the initial concentration of piperine used and [piperine $]_{\text {free }}$ is the concentration of piperine remain in the supernatant.

\subsection{Swelling Studies}

The swelling behaviour of the piperine-loaded starch nanoparticles was studied by immersed preweighted dried piperine loaded starch nanoparticles in $10 \mathrm{ml}$ of phosphate buffer saline (PBS) at $\mathrm{pH} 7.4$ and temperature $37^{\circ} \mathrm{C} \pm 0.5^{\circ} \mathrm{C}$. The weight of the swollen starch nanoparticles was determined at various time intervals. ${ }^{13}$ The swelling ratio was determined based on Equation 2:

$$
\text { Swelling ratio }(\mathrm{SR})=\frac{\mathrm{W}_{\mathrm{w}}-\mathrm{W}_{\mathrm{d}}}{\mathrm{W}_{\mathrm{d}}} \times 100 \%
$$

where $\mathrm{W}_{\mathrm{w}}$ and $\mathrm{W}_{\mathrm{d}}$ are the wet and dry weight of the starch nanoparticles, respectively.

\subsection{Piperine Release Analysis}

Approximately $50 \mathrm{mg}$ of piperine-loaded starch nanoparticles were dispersed in $20 \mathrm{ml}$ of PBS buffer solution ( $\mathrm{pH} 7.4$ ) at $37^{\circ} \mathrm{C} \pm 0.5^{\circ} \mathrm{C}$ by sonication. At predetermined time intervals, the solution was centrifuged and the supernatant was removed. The piperine loaded starch nanoparticles were re-dispersed in the same volume of fresh PBS buffer solution. The amount of piperine released in the supernatant was quantified using a UV/Vis spectrophotometer. The percentage of piperine released from starch nanoparticles was calculated with the Equation 3:

$$
\text { Release of piperine }(\%)=\frac{[\text { piperine }]_{\text {rel }}}{[\text { piperine }]_{\text {load }}} \times 100 \%
$$

where [piperine $]_{\text {rel }}$ is the concentration of piperine released and [piperine $]_{\text {load }}$ is the concentration of piperine loaded onto the starch nanoparticles. 


\section{RESULTS AND DISCUSSION}

\subsection{Synthesis of Piperine-loaded Starch Nanoparticles}

As shown in Figure 1(a), free piperine powders were insoluble in aqueous solution and floated on the surface of the aqueous solution. Whereas, piperine-loaded starch nanoparticles were fully dispersed in aqueous solution, shown in Figure 1(b). Loading of piperine onto starch nanoparticles has resulted in enhanced solubility of piperine in aqueous solution due to the highly hydrophilic nature, small-sized and large surface areas of the starch nanoparticles. The high surface area to volume ratio of starch nanoparticles also increased the interactions of piperine molecules with the aqueous solution, thus resulted in the observed enhanced solubility of the piperine in aqueous solution.
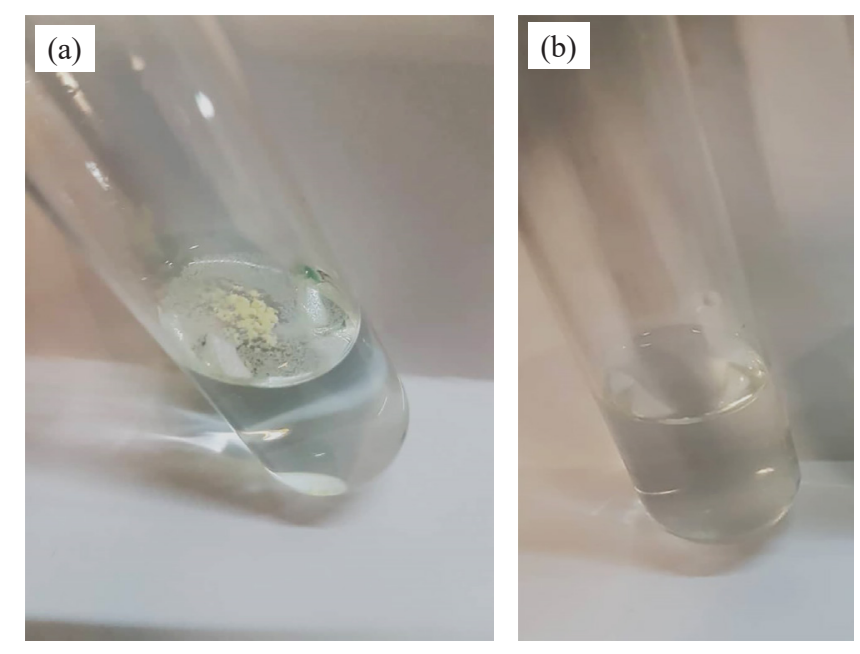

Figure 1: Photographic images of (a) free piperine powders floating on the surface of the aqueous solution indicating poor solubility of the powders, and (b) piperineloaded starch nanoparticles fully dispersed in aqueous solution.

As can be seen in Figure 2(a), native sago starch granules are mostly oval and granular in shape, with the granule sizes of around 20-40 $\mu \mathrm{m}$. Figure 2(b) shows the SEM image of piperine powders before loading onto starch nanoparticles. The piperine powders were observed to be in micro-sized powder aggregates. Figure 2(c) shows the FESEM of starch nanoparticles synthesised via the nanoprecipitation of starch solution into absolute ethanol. Starch nanoparticles were observed to be mainly in a spherical shape with particle size ranging between 28-97 nm and a mean diameter of $63 \mathrm{~nm} \pm 19 \mathrm{~nm}$ which is in consonance with reported results. ${ }^{14}$ Figure 2(d) shows a typical SEM micrograph of piperine- 
loaded starch nanoparticles, which was almost similar to the unloaded starch nanoparticles. The particle diameter of the piperine loaded starch nanoparticles was within the range of 52-154 $\mathrm{nm}$ and a mean particle diameter of $88 \mathrm{~nm} \pm 20 \mathrm{~nm}$.
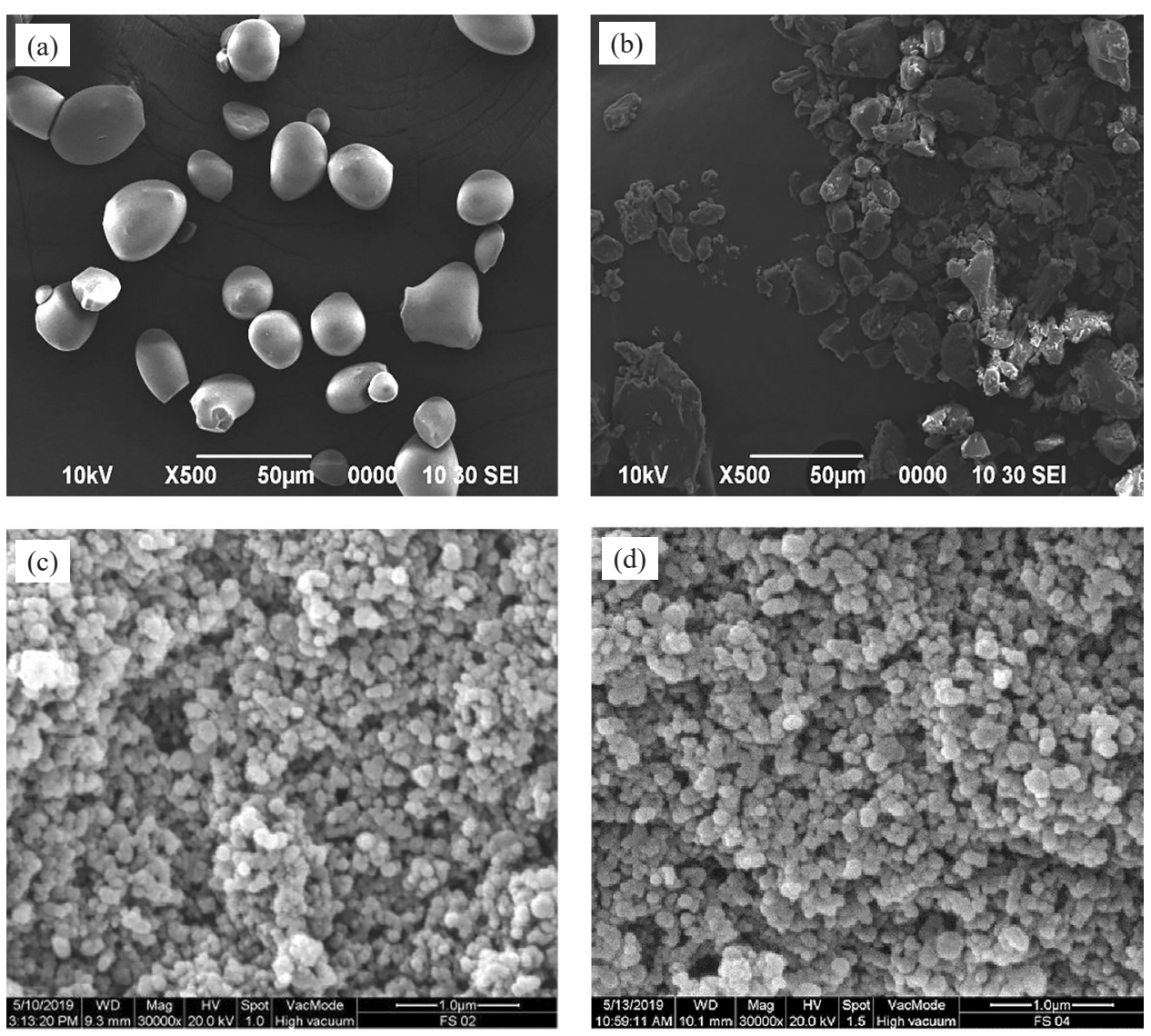

Figure 2: Illustrations of (a) SEM image of native sago starch powder, (b) SEM image of piperine powder, (c) FESEM image of starch nanoparticles, and (d) FESEM image of piperine-loaded starch nanoparticles.

\subsection{Effect of Surfactant Types on the Loading Capacity}

The effect of surfactant types used on the loading capacity of piperine was studied by using various types of surfactants, namely sorbitan monostearate (Span 60), polysorbate 80 (Tween 80 ) and CTAB. Figure 3 presents the effect of types of surfactants on the loading capacity of piperine onto starch nanoparticles. The concentration of all the surfactants used was $0.3 \mathrm{mg} \mathrm{ml}^{-1}$. Tween 80 and Span 60 
are non-ionic surfactants that are non-toxic in nature whereas CTAB is an anionic surfactant. Span 60 was observed to be the most effective surfactant for loading of piperine onto starch nanoparticles as shown by the highest loading capacity $2.268 \mathrm{mg} \mathrm{mg}^{-1}$ achieved when Span 60 was used as the surfactant. Span 60 was relatively more hydrophobic as compared to Tween 80 and CTAB. Piperine is a highly hydrophobic alkaloid and thus is more soluble in hydrophobic surfactant of Span 60 which resulted in the increase of loading capacity of piperine onto starch nanoparticles. ${ }^{14}$

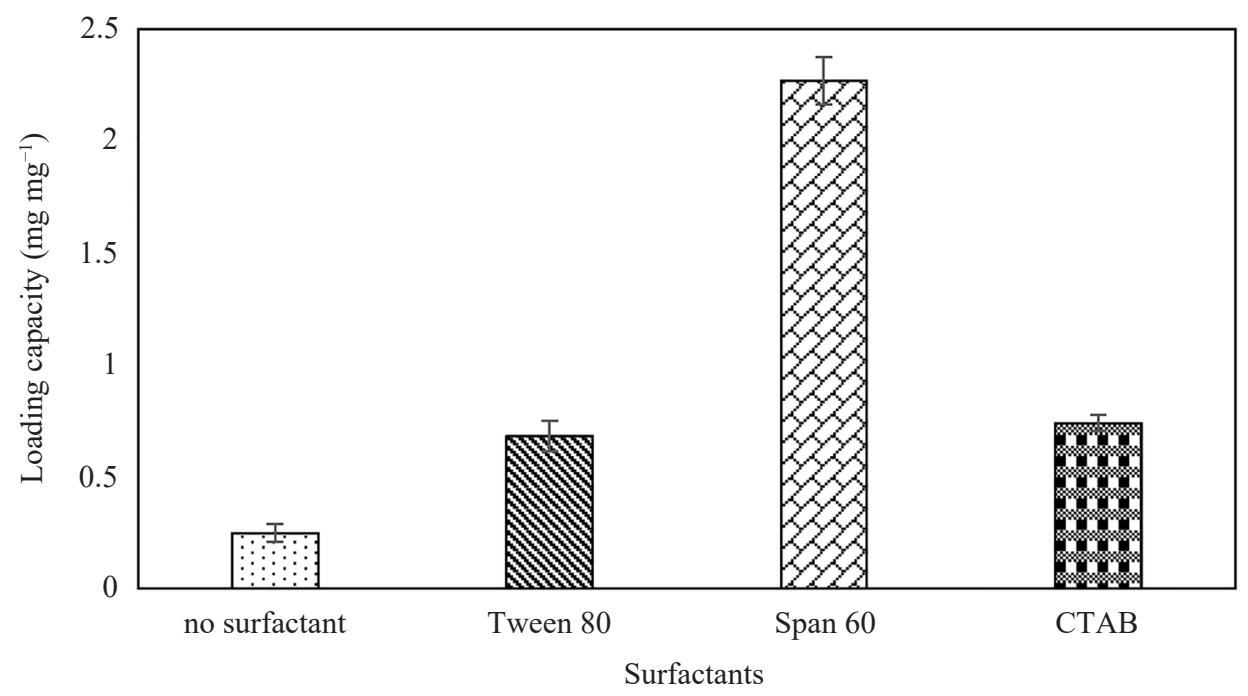

Figure 3: Effect of surfactants on the loading capacity of piperine onto starch nanoparticles (error bars were calculated from the mean value, $\mathrm{s} / \mathrm{n}=3$ ).

\subsection{Effect of Surfactant Concentration on the Loading Capacity}

The effect of different Span 60 concentrations on the loading capacity of piperine onto starch nanoparticles was shown in Figure 4. The highest loading capacity of piperine $\left(1.65 \mathrm{mg} \mathrm{mg}^{-1}\right)$ was achieved when $0.3 \mathrm{mg}^{-1}$ of Span 60 was used. Whereas, the lowest loading capacity was achieved when no surfactant was used. As the Span 60 concentration increased from 0 to $0.3 \mathrm{mg} \mathrm{ml}^{-1}$, the loading capacity of piperine was observed to increase linearly to the highest. However, as the surfactant concentration used was more than $0.3 \mathrm{mg} \mathrm{ml}^{-1}$, the loading capacity was observed to decrease which might be due to the high viscosity of Span $60 .{ }^{11}$ This indicated that the Span 60 surfactants critical micelle concentration was around $0.3 \mathrm{mg} \mathrm{ml}^{-1}$. Higher surfactant concentration would cause the formation of the micelle and reduced the surface tension of the starch nanoparticles, hence resulted in a decrease of the loading capacity of piperine onto starch nanoparticles. ${ }^{15}$ 


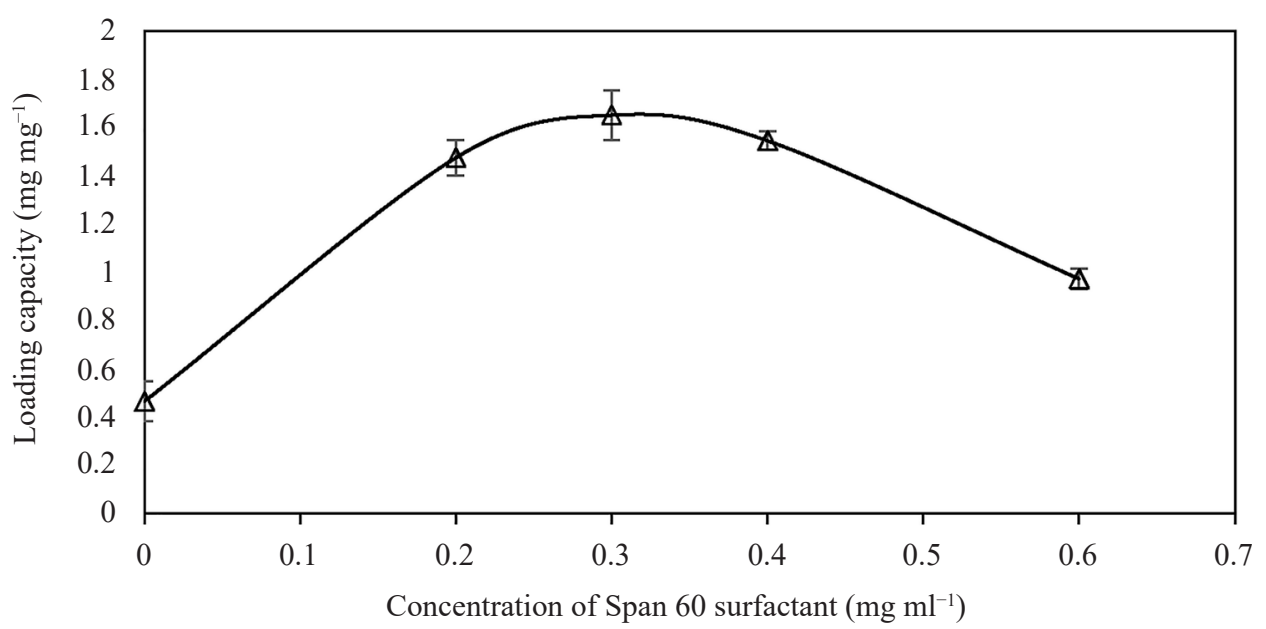

Figure 4: Effect of surfactant concentration on the loading capacity of piperine onto starch nanoparticles.

\subsection{Effect of Piperine Concentration on Loading Capacity}

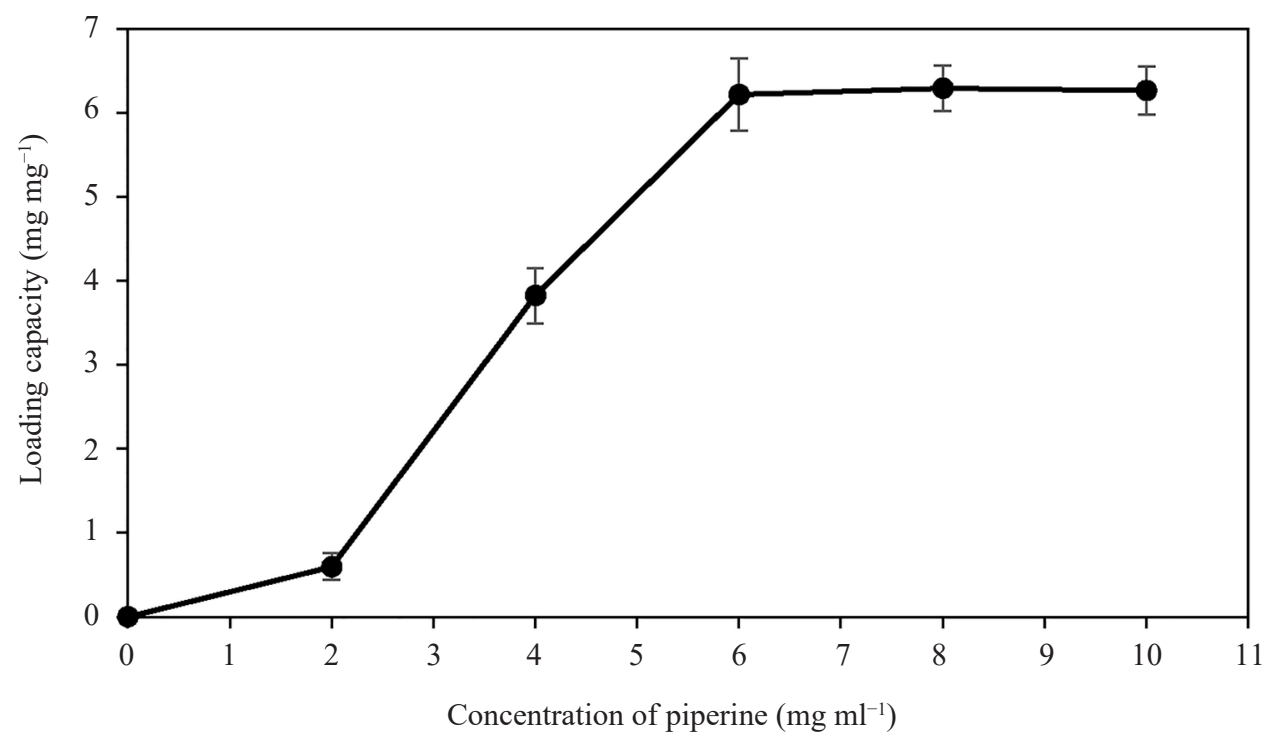

Figure 5: Effect of piperine concentration on the loading capacity of piperine onto starch nanoparticles (error bars were calculated from the mean value, $\mathrm{s} / \mathrm{n}=3$ ). 
Figure 5 presents the loading capacity of piperine onto starch nanoparticles at different concentrations of piperine. The loading capacity of piperine was observed to increase linearly from $0.59 \mathrm{mg} \mathrm{mg}^{-1}$ to $6.28 \mathrm{mg} \mathrm{mg}^{-1}$ as the concentration of piperine increased from $2.0 \mathrm{mg} \mathrm{ml}^{-1}$ to $6.0 \mathrm{mg} \mathrm{ml}^{-1}$. A maximum loading capacity of $6.29 \mathrm{mg} \mathrm{mg}^{-1}$ was obtained when $8.0 \mathrm{mg} \mathrm{ml}^{-1}$ of piperine was used. This result showed that starch nanoparticles have high potential as the piperine nanocarriers as evidenced by its high loading capacity. The nano-precipitation method used in this study has enabled a higher drug-loading capacity compared to the conventional absorption methods.

\subsection{Piperine Release Studies}

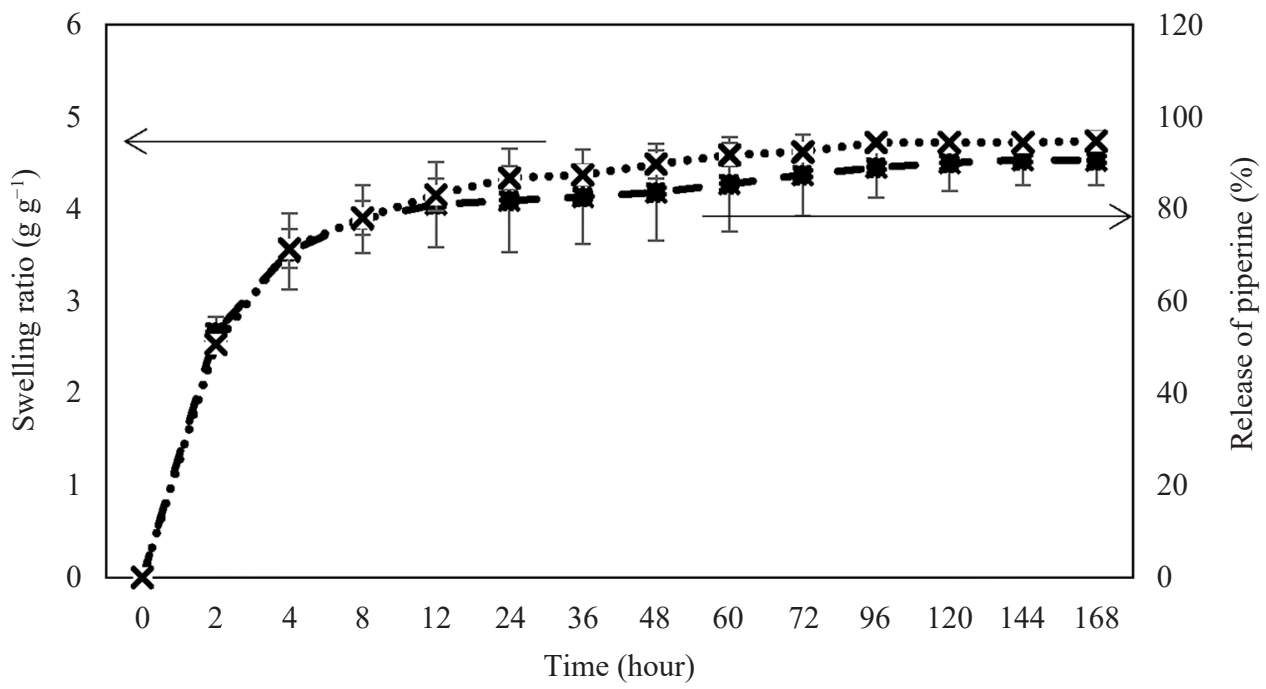

Figure 6: The swelling ratio of starch nanoparticles and release profile of piperine from starch nanoparticles as a function of time at $\mathrm{pH} 7.4$ (error bars were calculated from the mean value, $\mathrm{s} / \mathrm{n}=3$ ).

Figure 6 presents the swelling behaviour and release profile of piperine loaded sago starch nanoparticles in PBS buffer solution at $\mathrm{pH}$ 7.4. The release characteristics of piperine from sago starch nanoparticles were observed to have corresponded with the swelling behaviour of starch nanoparticles. Starch nanoparticles are highly hydrophilic in nature with an abundant of -OH group swelled very rapidly in the initial first $4 \mathrm{~h}$ when the swelling ratio is $4 \mathrm{~g} \mathrm{~g}^{-1}$ due to absorption of the buffer solution. In the first $4 \mathrm{~h}$, the initial burst release of piperine was observed and about $71 \%$ of piperine was observed to release out from the swollen starch nanoparticles very rapidly by the diffusion process. This could be due to the piperine that was absorbed on the outer surface or near the interior of the starch 
nanoparticles. However, after the burst release, piperine was observed to release gradually from starch nanoparticles over a period of $168 \mathrm{~h}$. As the swelling ratio of starch nanoparticles reached $4.5 \mathrm{~g} \mathrm{~g} \mathrm{~g}^{-1}$, around $94.6 \%$ of piperine had been released within a period of $168 \mathrm{~h}$. The sustain-release of piperine was due to the piperine diffused out from the core of the starch nanoparticles. Such a sustain release pattern is important in order to maintain the piperine concentration for a longer period of time. ${ }^{16}$ Figure 7 shows the correlation regression line studies of starch nanoparticles swelling ratio and piperine release, in which the $\mathrm{R}^{2}$ value was determined to be 0.9928 . This correlation study indicated that the release rates of piperine were linearly dependent on the swelling ratios of the starch nanoparticles.

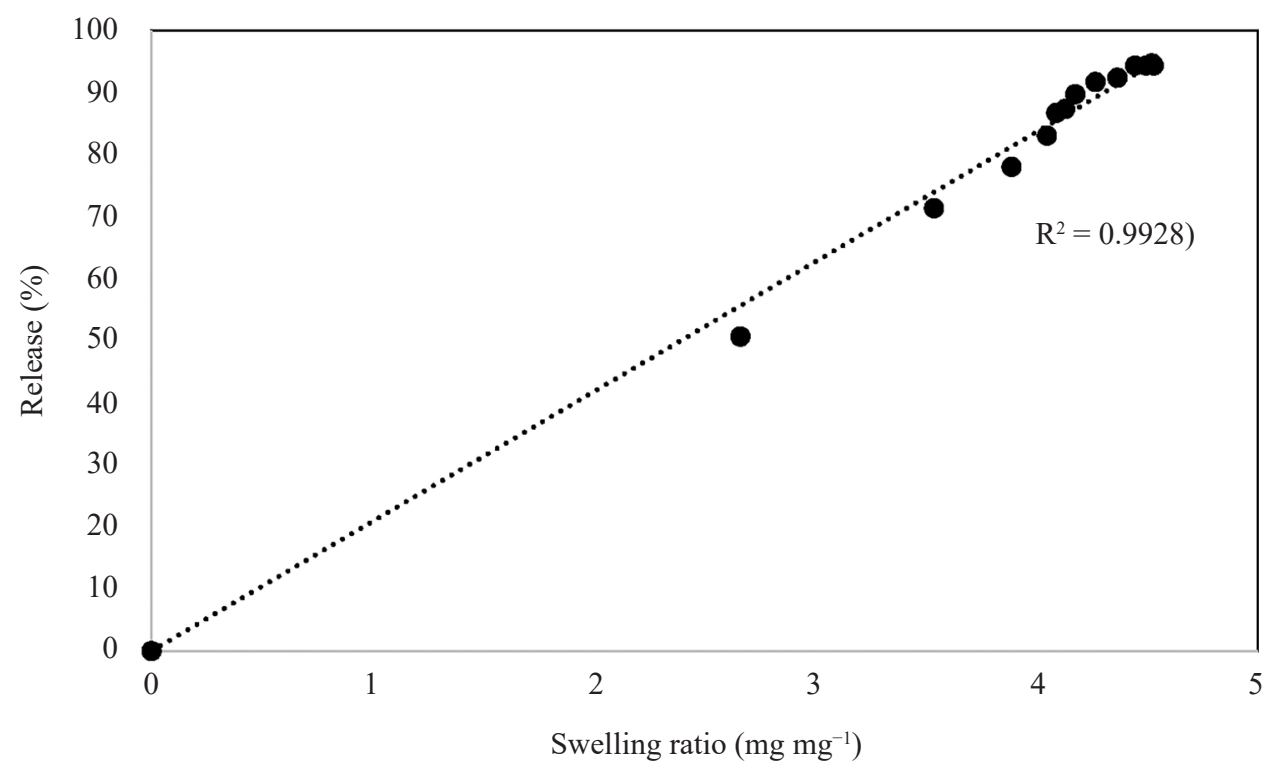

Figure 7: Correlation studies of swelling ratio vs. release profile of piperine from starch nanoparticles at $\mathrm{pH} 7.4$.

\section{CONCLUSION}

In conclusion, we have successfully synthesised piperine-loaded starch nanoparticles through the nano-precipitation method. The loading capacity could be optimised by judicious choice of types of surfactants and initial concentrations of piperine used. Loading of piperine onto starch nanoparticles was observed to enhance the solubility of piperine in the aqueous medium. Our studies demonstrated that piperine could be control-released from starch nanoparticles under the physiological conditions, thus starch nanoparticles are the potential nanocarriers for piperine. 


\section{ACKNOWLEDGEMENTS}

Financial support by Tun Openg Chair (F07/TOC/1511/2016) is gratefully acknowledged.

\section{REFERENCES}

1. Gogani, L. et al. (2016). Piperine - The bioactive compound of black pepper: From isolation to medicinal formulations. Comp. Rev. Food Sci. Food Saf., 16(1), 124 140. https://doi.org/10.1111/1541-4337.12246

2. Chinta, G. et al. (2015). Piperine: A comprehensive review of pre-clinical and clinical investigation. Curr. Bioact. Comp., 11(3), 156-169. https://doi.org/10.217 4/1573407211666150915214425

3. Pachauri, M., Gupta, E. D. \& Ghosh, P. C. (2015). Piperine loaded PEG-PLGA nanoparticles: Preparation, characterization and targeted delivery for adjuvant breast cancer chemotherapy. J. Drug Del. Sci. Tech., 29, 269-282. https://doi. org/10.1016/j.jddst.2015.08.009

4. Elnaggar, Y. S. R. et al. (2015). Intranasal piperine-loaded chitosan nanoparticles as brain-targeted therapy in alzheimer's diesease: Optimization biological efficacy, and potential toxicity. J. Pharm. Sci., 104(10), 3544-3556. https://doi.org/10.1002/ jps.24557

5. Bhalekar, M. R. et al. (2017). Formulation of piperine solid lipid nanoparticles (SLN) for treatment of rheumatoid arthritis. Drug Dev. Ind. Pharm., 43(6), 10031010. https://doi.org/10.1080/03639045.2017.1291666

6. Anissian, D. et al. (2017). Piperine-loaded chitosan-STPP nanoparticles reduce neuronal loss and astrocytes activation in chemical kindling model of epilepsy. Int. J. Biol. Macromol., 107, 973-983. https://doi.org/10.1016/j.ijbiomac.2017.09.073

7. Ramirez, Y. I. C. et al. (2018). The structural characteristics of starches and their functional properties. J. Food, 16(1), 1003-1017. https://doi.org/10.1080/194763 37.2018.1518343

8. Egharevba, H. O. (2019). Chemical properties of starch and its application in the food industry. IntechOpen, 16-17. https://doi.org/10.5772/intechopen.87777

9. Kim, H. Y., Park, S. S. \& Lim, S. T. (2014). Preparation and utilization of starch nanoparticles. Coll. Surf. B Biointerf., 126, 607-620. https://doi.org/10.1016/j. colsurfb.2014.11.011

10. Pang, S. C. et al. (2015). Fabrication of polysaccharide-base nanoparticles as drug delivery nanocarriers. ECS Trans., 66(37), 15-32. https://doi. org/10.1149/06637.0015ecst

11. Chin, S. F., Yazid, S. N. A \& Pang, S. C. (2014). Preparation and characterization of starch nanoparticles for controlled release of curcumin. Int. J. Polym. Sci., Article ID 340121. https://doi.org/10.1155/2014/340121

12. Pang, S. C., Tay, S. H. \& Chin, S. F. (2014). Facile synthesis of curcumin-loaded starch-maleate nanoparticles. J. Nanomater., Article ID 824025. https://doi. org/10.1155/2014/824025 
13. Chin, S. F. et al. (2019). pH-responsive starch-citrate nanoparticles for controlled release of paracetamol. Starch, 71(9-10), 1800336. https://doi.org/10.1002/ star.201800336

14. Chin, S. F., Azman, A. \& Pang, S. C. (2014). Size controlled synthesis of starch nanoparticles by microemulsion method. J. Nanomater., Article ID 763736. https://doi.org/10.1155/2014/763736

15. Michor, E. L. \& Berg, J. C. (2015). Temperature effects on micelle formation and particles charging with span surfactants in apolar media. Langm., 31, 9602-9607. https://doi.org/10.1021/acs.langmuir.5b02711

16. Dutta, S. \& Bhattacharjee P. (2017). Nanoliposomal encapsulates of piperinerich black pepper extract obtained by enzyme-assisted supercritical carbon dioxide extraction. J. Food Eng., 201, 49-56. https://doi.org/10.1016/j. jfoodeng.2017.01.006 